\title{
The role of osteopontin expression in melanoma progression
}

\author{
Timea Kiss ${ }^{1}$, Szilvia Ecsedi ${ }^{1,2}$, Laura Vizkeleti ${ }^{1,2}$, Viktoria Koroknai ${ }^{1}$, Gabriella Emri ${ }^{3}$, \\ Nora Kovács ${ }^{1}$, Roza Adany ${ }^{1,2}$, and Margit Balazs ${ }^{1,2}$ \\ ${ }^{1}$ Department of Preventive Medicine, Faculty of Public Health, University of Debrecen, \\ Debrecen, Hungary \\ ${ }^{2}$ MTA-DE Public Health Research Group, University of Debrecen, Debrecen, Hungary \\ ${ }^{3}$ Department of Dermatology, Faculty of Medicine, University of Debrecen, Debrecen, \\ Hungary
}

Corresponding author: Margit Balazs, Department of Preventive Medicine, Faculty of Public Health, University of Debrecen, Debrecen, Hungary, H-4028 Debrecen, Kassai str. 26/b., Hungary;

E-mail: balazs.margit@sph.unideb.hu

Running title: OPN in cutaneous melanoma

Keywords: melanoma progression, osteopontin, protein expression, tissue microarray 


\begin{abstract}
It was shown that osteopontin (OPN), a glycophosphoprotein, plays divergent roles in cancer progression. In addition to multiple intra- and extracellular functions, it facilitates migration of tumor cells, has crucial role in cell adhesion and is associated with increased metastasis formation. In previous studies, we performed global gene-expression profiling on a series of primary melanoma samples and found that OPN was significantly overexpressed in ulcerated melanomas. The major purpose of this study was to define OPN expression in primary melanomas with differing biological behaviours. OPN mRNA expression was analysed by quantitative reverse transcription polymerase chain reaction (qRT-PCR) in primary melanoma tissues. Immunohistochemistry was performed using a tissue microarray. Cox regression tests were used for survival analysis. Greater than $50 \%$ of the tissues exhibited high protein expression that was significantly associated with tumor thickness and metastasis. OPN mRNA expression was significantly increased in thicker melanomas and lesions with an ulcerated surface. Increased expression was primarily detected in advanced-stage tumors. A multivariate Cox regression analysis revealed that high OPN expression, tumor thickness, and metastasis were significantly associated with reduced relapse-free survival. In summary, high OPN mRNA and protein expression were associated with a less favourable clinical outcome of primary melanoma patients. We determined that OPN is a significant predictive factor for the survival of primary melanoma patients. Based on our and others data the high expression of OPN may have a crucial stimulatory role in tumor progression and metastasis formation, thus, have been proposed as potential targets for cancer diagnosis and therapy.
\end{abstract}




\section{Introduction}

Malignant melanoma is the most aggressive type of skin cancer, with rapidly increasing incidence worldwide [1-3]. Despite previous intensive research to advance our understanding of melanoma progression, therapeutic options remain limited, and melanoma is mainly cured surgically $[4,5]$. New therapeutic targets and diagnostic tools are especially warranted.

Osteopontin (OPN) is a multifunctional extracellular matrix protein that is produced by numerous cell types [6-11]. OPN plays important roles in cancer cell adhesion, cell motility, and survival [12-16]. Previous reports indicated that the OPN is a crucial participant in the regulation of cancer cell signalling, ultimately leading to tumor progression [17-22].

Several studies indicate that OPN protein is overexpressed in the majority of human cancers, including malignant melanoma, and is associated with tumor progression [14, 23-30]. Extensive microarray analyses of melanomas demonstrated that $O P N$ also plays a role in melanoma progression $[14,28,31,32]$.

Several research groups have studied OPN expression at both the protein and mRNA levels in primary and metastatic melanomas and demonstrated that OPN expression is significantly increased in melanoma samples compared with naevi [14, 28, 31]. One of these studies did not identify an association between protein expression level and the clinicopathological parameters of primary melanoma tumors [14]. Other studies have reported that OPN was significantly overexpressed in primary and metastatic melanomas, but none of these studies reported an unequivocal correlation among OPN expression levels and the primary melanoma thickness, stage, and relapse-free survival [24]. According to the majority of the studies, OPN is a specific tumor marker candidate; therefore, OPN might serve as a potential target for therapeutic intervention to control melanoma progression [24, 33, 34]. However, the prognostic relevance of OPN in melanoma has not been fully elucidated.

In previous studies, we performed global gene-expression profiling on a series of primary melanoma samples and report that $O P N$ was significantly associated with poor clinical outcome [35]. In this study, our aim was to confirm our previous microarray data; furthermore, we sought to elucidate OPN expression at both the mRNA and protein levels in primary melanoma samples using quantitative polymerase chain 
reaction (PCR), tissue microarray, and immunohistochemistry. To characterise the clinical parameters that might impact molecular alterations, we also aimed to define the association between OPN expression and the clinicopathological parameters of melanoma patients. Furthermore, we analysed the relationship between OPN expression and melanoma patient survival.

\section{Material and Methods}

\section{Melanoma tissue samples}

Melanoma tissues were obtained from the Department of Dermatology, University of Debrecen, Hungary. This study was approved by the Regional and Institutional Ethics Committee of the University of Debrecen Clinical Center and performed according to the relevant regulations. Written informed consent was obtained from the patients. Lesions were diagnosed based on formalin-fixed paraffin-embedded (FFPE) tissue sections that were stained with haematoxylin-eosin (H\&E). A total of 93 tumors were examined using immunohistochemistry, 28 tumors were analysed by real-time quantitative reverse transcription polymerase chain reaction (qRT-PCR), and 14 tumors were analysed using both methods. The clinicopathological data of the primary melanomas are summarised in Table 1.

\section{RNA extraction and qRT-PCR}

The RNeasy Mini Kit (Qiagen GmbH, Hilden, Germany) was used to isolate the total RNA from 28 fresh melanoma tissues according to the manufacturer's protocol. The quantities of the RNA samples were determined using a NanoDrop ND-1000 UV-Vis Spectrophotometer (NanoDrop Technologies, Wilmington, DE, USA). Reverse transcription (RT) was performed on total RNA (600 ng) using the High-Capacity cDNA Reverse Transcription Kit according to the manufacturer's protocol (Life Technologies Corporation, Carlsbad, California, USA). TaqMan one-step RT-PCR was used to determine the mRNA level of the $O P N$ gene. Each reaction contained $150 \mathrm{ng}$ of total sample RNA, and the reactions were run in triplicate on an ABI-PRISM 7000 instrument (Applied Biosystems, Carlsbad, CA, USA). PCR Master Mix and assays (Hs00167093_m1 OPN targeting the exon 3-4 boundary) were obtained from Life Technologies. PCR data were analysed using the Livak method $\left(2^{-\Delta \Delta C t}\right)$ using glyceraldehyde-3-phosphate dehydrogenase (GAPDH; Hs99999905_m1) and beta-actin 
(ACTB; Hs99999903_m1) as the reference (endogenous controls) genes and naevi as the calibrator sample [36].

\section{Tissue microarrays and immunohistochemistry}

A total of 93 FFPE melanomas were included in the tissue microarray analysis (TMA) [37]. The clinicopathological data of the primary melanomas are summarised in Table 1. Tissue sections $(4 \mu \mathrm{m})$ of the original blocks were first stained with H\&E and then reviewed by pathologists to select the area to be punched automatically using the TMA Master (Carl Zeiss, Jena, Germany). We used triplicate 1-mm tumor cores from each donor block. Serial sections of $4 \mu \mathrm{m}$ were excised from the TMA blocks and used for immunohistochemical investigations following $H \& E$ validation of the sample spots. After deparaffinisation and blocking the endogenous peroxidases $\left(1 \% \mathrm{H}_{2} \mathrm{O}_{2}\right.$ for $10 \mathrm{~min}$ at RT) and non-specific binding sites, we retrieved antigens in $1 \mathrm{mM}$ boiling citrate buffer ( $\mathrm{pH} \mathrm{6,3} \mathrm{min}$ ). Then, the primary antibody, rabbit polyclonal anti-osteopontin IgG (Thermo Scientific, USA), was added at a 1:20 dilution and incubated for $1 \mathrm{~h}$ at room temperature (RT). After incubation with the primary antibody, the samples were stained using the Envision detection system (DAKO Inc., Carpinteria, CA, USA) and the VIP Peroxidase Substrate Kit (Vector Laboratories LTD, Peterborough, UK). The nuclei were counterstained with methyl green (Vector Laboratories LTD, Peterborough, UK). The primary antibody was omitted in negative controls. The HeLa cervical cancer cell line was used as a positive control. The slides were digitised using the MiraxScan slide scanning device (Carl Zeiss, Jena, Germany) as previously described [38]. Digital images were displayed using MiraxViewer software (Carl Zeiss, Jena, Germany) and evaluated by two dermatopathologists who were blind with respect to the sample data. We determined the tumor cell proportion score and intensity score. The proportion score included the fraction of positively stained tumor cells as follows: $0=$ none, $1+=<5 \%$, $2+=5-50 \%$, and $3+=>50 \%$. The estimated average staining intensity of the positive tumor cells was expressed as follows: $0=$ none, $1+=$ weak, $2+=$ moderate, and $3+=$ strong (Figure 1).

\section{Statistical analysis}

SPSS (Statistical Package for the Social Sciences) 22.0 software (SPSS Inc., Chicago, IL, USA) was used for statistical analysis. Fisher's exact and Mann-Whitney-Wilcoxon tests were used to compare OPN expression and clinicopathological data of the primary 
tumors. To analyse the relationship between qRT-PCR data and clinicopathological parameters of melanoma patients, we used Mann-Whitney-Wilcoxon tests. Fisher's exact test was performed for the statistical analysis of protein expression data. The predictors of survival were evaluated with a Cox regression analysis. Survival times were calculated as the time from diagnosis to the last follow-up or death. Logistic regression was used to analyse the association between prognostic factors and the formation of metastasis. A p value $<0.05$ was considered statistically significant.

\section{Results}

\section{OPN mRNA expression in primary melanomas}

OPN gene expression analysis was performed in 28 primary melanomas. A greater than two-fold increase in the OPN mRNA level was found in 93\% (26/28) of these melanomas. We determined the relationship between gene expression levels and clinicopathological parameters. OPN mRNA expression was significantly increased in thicker melanomas (greater than $4.00 \mathrm{~mm}$ ) and ulcerated lesions; furthermore, OPN was present mainly in late-stage tumors (Clark levels IV and V) (Figure 2).

Fourteen overlapping samples were used to compare the gene- and protein-expression levels in the same tumor samples (Table 2). Increased OPN mRNA expression levels were detected in the majority of primary melanoma samples and were associated with different degrees of protein expression. A few contradictions may result from the fact that the samples used for the qRT-PCR and immunohistochemical study were derived from a part of the tumor that exhibits significant normal cell contamination. We did not observe any correlation between OPN protein levels and mRNA expression.

\section{Association between OPN protein expression and clinicopathological characteristics in primary melanomas}

We examined OPN protein expression levels in 93 primary melanomas. In total, $87 \%$ (81/93) of the melanoma samples were positive for OPN. The remaining 12 samples showed no OPN positivity. Greater than $50 \%$ of primary melanomas with poor clinical outcome exhibited increased OPN protein expression. Primary lesions in which at least $50 \%$ of the tumor cells showed high OPN expression were associated with unfavourable prognosis (nodular subtype, advanced stage, > $4.01 \mathrm{~mm}$ thickness, ulcerated surface, metastasis formation, and $<5$-year survival). OPN positivity 
exhibited a significant correlation with Breslow tumor thickness and metastasis $(\mathrm{p}=$ 0.021 and $\mathrm{p}=0.036$, respectively, Table 3). Melanoma samples with poor clinical outcome showed stronger OPN staining. We analysed the relationship between OPN expression levels and clinicopathological data of the primary tumors. Increased OPN expression was significantly associated with increasing tumor thickness $(p=0.007$, proportion of tumor cells and Breslow thickness; $\mathrm{p}=0.033$, staining intensity and Breslow thickness). We assessed the effect of OPN expression and prognostic factors on metastasis formation using multivariate logistic regression analyses. These results indicate that melanomas with OPN expression exhibited a 1.39-fold increased risk of metastasis, but this association was not significant $(\mathrm{p}=0.691)$. However, Breslow thickness $(\mathrm{p}=0.032)$ and ulceration $(\mathrm{p}=0.002)$ were significantly associated with metastasis (Table 4).

Multivariate Cox regression analyses of survival were performed regarding OPN expression levels and various prognostic factors such as ulceration, Breslow thickness and metastatic potential. In this analysis, we demonstrated that high OPN expression ( score of 2 or 3 ) [hazard ratio $(\mathrm{HR})=2.02 ; 95 \%$ confidence interval $(\mathrm{CI})=0.99-4.14$; $\mathrm{p}=0.050]$, tumor thickness $[\mathrm{HR}=1.66 ; 95 \% \mathrm{CI}=1.01-2.74 ; \mathrm{p}=0.046]$, and metastasis $[\mathrm{HR}=14.25 ; 95 \% \mathrm{CI}=4.98-40.77 ; \mathrm{p}<0.001]$ were significantly associated with reduced melanoma patient survival.

\section{Discussion}

In the last decade, several studies have defined the important role of OPN in tumorigenesis and metastasis. In human malignant melanoma, OPN expression is significantly associated with reduced relapse-free survival and additional histological parameters that are associated with poor clinical outcome [7, 24, 29, 33]. OPN is a prognostic marker in a variety of cancers [30, 39-41]. In metastatic and primary melanomas, OPN has also been suggested to be a novel promising biomarker for the detection of metastases in patients with primary melanomas [24, 42-45]. Atai et al. performed a meta-analysis across several distinct cancer microarray data sets and found increased $O P N$ gene expression in at least $90 \%$ of melanoma patients[46].

Our group recently published a comprehensive microarray analysis in primary melanomas and reported that increased OPN mRNA expression in melanomas is 
characteristic of less-favourable clinical outcomes [35]. Our present study successfully validated the aforementioned microarray results by qRT-PCR, revealing that increased OPN mRNA expression is significantly associated with later-stage melanomas (Clark levels IV-V) with an ulcerated surface and higher thickness (greater than $4.00 \mathrm{~mm}$ ). Previous studies have reported that increased OPN mRNA expression is associated with unfavourable patient prognosis in human cancers, including melanoma [9, 29]. In addition, we extended our studies to OPN protein levels and therefore fabricated tissue microarray platforms for 93 primary melanomas. By performing immunohistochemistry on the primary melanoma specimens, we observed increased OPN protein levels in samples with poor prognosis. Notably, increasing immunostaining was significantly associated with Breslow tumor thickness and metastatic capacity, indicating a role for OPN in melanoma progression [7, 24]. However, our protein and gene expression results did not reveal clear relationships in all samples, and on average, we observed that increased OPN mRNA levels were associated with strong antigen positivity. The main reason for this phenomenon might be due to the relatively limited number of melanoma specimens. Several previous studies have simultaneously investigated OPN mRNA and protein expression in various cancers, including melanoma, and found that OPN was overexpressed in tumors that were associated with less favourable prognoses $[9,28,31,32]$. A logistic regression analysis revealed increased metastasis in thicker melanomas [odds ratio $(\mathrm{OR})=3.11 ; 95 \%$ confidence interval $(\mathrm{CI})=1.10-8.75$; $\mathrm{p}=0.032]$ and ulcerated lesions $(\mathrm{OR}=5.47 ; 95 \% \mathrm{CI}=1.85-16.17 ; \mathrm{p}=0.002)$. In a multivariate Cox regression analysis, increased OPN expression emerged as a predictor of survival after thickness and metastasis. Patients with increased OPN expression (a score of 2 or 3 ) exhibited a 2.02-fold increased risk of death from disease $(p=0.050)$, which is consistent with that described in the literature [15, 24]. Elevated OPN expression is associated with advanced stage, tumor invasion, and metastasis in multiple cancers. The function of OPN is versatile and involves the induction of multiple signalling pathways (PI 3'-kinase/Akt, NF-kB) by integrin and CD44 receptors that mediate metastatic processes $[8,18,19]$.

In summary, we demonstrate that tumor OPN expression is a strong predictor of poor prognosis. A multivariate analysis confirmed that OPN is a significant predictive factor for primary melanoma patient survival. This study provides further evidence regarding 
the importance of OPN in the biology of melanoma. Our findings are consistent with those of previous studies and support the hypothesis that OPN expression is a potential biomarker of melanoma progression $[29,33]$.

\section{Acknowledgments}

This research was supported by the Hungarian National Research Fund (OTKA K75191), the Hungarian Academy of Sciences (grant number 2011 TKI 473), TÁMOP4.2.2/B-10/1-2010-0024 and TÁMOP-4.2.2.A-11/1/KONV-2012-0031 projects; the TÁMOP projects are co-financed by the European Union and the European Social Fund. This research was also supported by the European Union and the State of Hungary, co-financed by the European Social Fund in the framework of the TÁMOP4.2.4.A/2-11/1-2012-0001 'National Excellence Program'. The authors have no connection with any of the companies or products mentioned in this article.

\section{Figure legends}

Figure 1. Scoring system for immunostaining intensity of primary melanoma tissues. The staining intensity of OPN in melanoma samples with no / 0 (a), weak / 1+ (b), medium / $2+$ (c) and high / 3+ (d) level protein expression.

Figure 2. $\log _{2}$ - transformed OPN mRNA levels in melanomas relative to control naevus. Significant difference between clinical-pathological parameters and gene expression levels. The mRNA expression of OPN was significantly higher in late stage melanomas with ulcerated tumor surface and higher thickness.

\section{References}

1 Forschner A, Eigentler TK, Pflugfelder A, Leiter U, Weide B, Held L, Meier F, Garbe C: Melanoma staging: Facts and controversies. Clin Dermatol 2010;28:275-280. 
2 Godar DE: Worldwide increasing incidences of cutaneous malignant melanoma. J Skin Cancer;2011:858425.

3 Macdonald JB, Dueck AC, Gray RJ, Wasif N, Swanson DL, Sekulic A, Pockaj BA: Malignant melanoma in the elderly: Different regional disease and poorer prognosis. J Cancer 2011;2:538-543.

4 Chin L, Garraway LA, Fisher DE: Malignant melanoma: Genetics and therapeutics in the genomic era. Genes Dev 2006;20:2149-2182.

5 Lee B, Mukhi N, Liu D: Current management and novel agents for malignant melanoma. J Hematol Oncol 2012;5:3.

6 Koh A, da Silva AP, Bansal AK, Bansal M, Sun C, Lee H, Glogauer M, Sodek J, Zohar R: Role of osteopontin in neutrophil function. Immunology 2007;122:466-475.

7 Buback F, Renkl AC, Schulz G, Weiss JM: Osteopontin and the skin: Multiple emerging roles in cutaneous biology and pathology. Experimental dermatology 2009; 18:750-759.

8 Wai PY, Kuo PC: Osteopontin: Regulation in tumor metastasis. Cancer metastasis reviews 2008;27:103-118.

9 Rittling SR, Chambers AF: Role of osteopontin in tumour progression. British journal of cancer 2004;90:1877-1881.

10 Sodek J, Ganss B, McKee MD: Osteopontin. Crit Rev Oral Biol Med 2000;11:279-303.

11 Wang KX, Denhardt DT: Osteopontin: Role in immune regulation and stress responses. Cytokine Growth Factor Rev 2008;19:333-345.

12 Hsieh YH, Juliana MM, Hicks PH, Feng G, Elmets C, Liaw L, Chang PL: Papilloma development is delayed in osteopontin-null mice: Implicating an antiapoptosis role for osteopontin. Cancer Res 2006;66:7119-7127.

13 Standal T, Borset M, Sundan A: Role of osteopontin in adhesion, migration, cell survival and bone remodeling. Exp Oncol 2004;26:179-184.

14 Zhou Y, Dai DL, Martinka M, Su M, Zhang Y, Campos EI, Dorocicz I, Tang L, Huntsman D, Nelson C, Ho V, Li G: Osteopontin expression correlates with melanoma invasion. The Journal of investigative dermatology 2005;124:1044-1052.

15 Weber GF, Lett GS, Haubein NC: Osteopontin is a marker for cancer aggressiveness and patient survival. British journal of cancer 2010;103:861-869.

16 El-Tanani MK, Campbell FC, Kurisetty V, Jin D, McCann M, Rudland PS: The regulation and role of osteopontin in malignant transformation and cancer. Cytokine Growth Factor Rev 2006;17:463-474.

17 Das R, Philip S, Mahabeleshwar GH, Bulbule A, Kundu GC: Osteopontin: It's role in regulation of cell motility and nuclear factor kappa b-mediated urokinase type plasminogen activator expression. IUBMB Life 2005;57:441-447.

18 Packer L, Pavey S, Parker A, Stark M, Johansson P, Clarke B, Pollock P, Ringner M, Hayward N: Osteopontin is a downstream effector of the pi3-kinase pathway in melanomas that is inversely correlated with functional pten. Carcinogenesis 2006;27:1778-1786.

19 Rangaswami H, Bulbule A, Kundu GC: Osteopontin: Role in cell signaling and cancer progression. Trends Cell Biol 2006;16:79-87.

20 Bellahcene A, Castronovo V, Ogbureke KU, Fisher LW, Fedarko NS: Small integrin-binding ligand n-linked glycoproteins (siblings): Multifunctional proteins in cancer. Nat Rev Cancer 2008;8:212-226. 
21 Song G, Ouyang G, Bao S: The activation of akt/pkb signaling pathway and cell survival. J Cell Mol Med 2005;9:59-71.

22 Shevde LA, Das S, Clark DW, Samant RS: Osteopontin: An effector and an effect of tumor metastasis. Curr Mol Med 2010;10:71-81.

23 Kazanecki CC, Uzwiak DJ, Denhardt DT: Control of osteopontin signaling and function by post-translational phosphorylation and protein folding. J Cell Biochem 2007;102:912-924.

24 Rangel J, Nosrati M, Torabian S, Shaikh L, Leong SP, Haqq C, Miller JR, 3rd, Sagebiel RW, Kashani-Sabet M: Osteopontin as a molecular prognostic marker for melanoma. Cancer 2008;112:144-150.

25 Schultz J, Lorenz P, Ibrahim SM, Kundt G, Gross G, Kunz M: The functional $443 \mathrm{t} / \mathrm{c}$ osteopontin promoter polymorphism influences osteopontin gene expression in melanoma cells via binding of c-myb transcription factor. Mol Carcinog 2009;48:14-23.

26 Tuck AB, Chambers AF, Allan AL: Osteopontin overexpression in breast cancer: Knowledge gained and possible implications for clinical management. J Cell Biochem 2007;102:859-868.

27 Denhardt D: Osteopontin expression correlates with melanoma invasion. J Invest Dermatol 2005;124:xvi-xviii.

28 Haqq C, Nosrati M, Sudilovsky D, Crothers J, Khodabakhsh D, Pulliam BL, Federman S, Miller JR, 3rd, Allen RE, Singer MI, Leong SP, Ljung BM, Sagebiel RW, Kashani-Sabet M: The gene expression signatures of melanoma progression. Proc Natl Acad Sci U S A 2005;102:6092-6097.

29 Conway C, Mitra A, Jewell R, Randerson-Moor J, Lobo S, Nsengimana J, Edward S, Sanders DS, Cook M, Powell B, Boon A, Elliott F, de Kort F, Knowles MA, Bishop DT, Newton-Bishop J: Gene expression profiling of paraffin-embedded primary melanoma using the dasl assay identifies increased osteopontin expression as predictive of reduced relapse-free survival. Clinical cancer research : an official journal of the American Association for Cancer Research 2009;15:6939-6946.

30 Rodrigues LR, Teixeira JA, Schmitt FL, Paulsson M, Lindmark-Mansson H: The role of osteopontin in tumor progression and metastasis in breast cancer. Cancer Epidemiol Biomarkers Prev 2007;16:1087-1097.

31 Smith AP, Hoek K, Becker D: Whole-genome expression profiling of the melanoma progression pathway reveals marked molecular differences between nevi/melanoma in situ and advanced-stage melanomas. Cancer Biol Ther 2005;4:10181029.

32 Jaeger J, Koczan D, Thiesen HJ, Ibrahim SM, Gross G, Spang R, Kunz M: Gene expression signatures for tumor progression, tumor subtype, and tumor thickness in laser-microdissected melanoma tissues. Clinical cancer research : an official journal of the American Association for Cancer Research 2007;13:806-815.

33 Mitra A, Conway C, Walker C, Cook M, Powell B, Lobo S, Chan M, Kissin M, Layer G, Smallwood J, Ottensmeier C, Stanley P, Peach H, Chong H, Elliott F, Iles MM, Nsengimana J, Barrett JH, Bishop DT, Newton-Bishop JA: Melanoma sentinel node biopsy and prediction models for relapse and overall survival. British journal of cancer 2010;103:1229-1236.

34 Weber GF: The metastasis gene osteopontin: A candidate target for cancer therapy. Biochim Biophys Acta 2001;1552:61-85. 
35 Rakosy Z, Ecsedi S, Toth R, Vizkeleti L, Hernandez-Vargas H, Lazar V, Emri G, Szatmari I, Herceg Z, Adany R, Balazs M: Integrative genomics identifies gene signature associated with melanoma ulceration. PLoS One 2013;8:e54958.

36 Livak KJ, Schmittgen TD: Analysis of relative gene expression data using realtime quantitative pcr and the 2(-delta delta $\mathrm{c}(\mathrm{t})$ ) method. Methods 2001;25:402-408.

37 Koh SS, Opel ML, Wei JP, Yau K, Shah R, Gorre ME, Whitman E, Shitabata PK, Tao Y, Cochran AJ, Abrishami P, Binder SW: Molecular classification of melanomas and nevi using gene expression microarray signatures and formalin-fixed and paraffin-embedded tissue. Mod Pathol 2009;22:538-546.

38 Lueking A, Beator J, Patz E, Mullner S, Mehes G, Amersdorfer P: Determination and validation of off-target activities of anti-cd44 variant 6 antibodies using protein biochips and tissue microarrays. Biotechniques 2008;45:Pi-v.

39 Rud AK, Boye K, Oijordsbakken M, Lund-Iversen M, Halvorsen AR, Solberg SK, Berge G, Helland A, Brustugun OT, Maelandsmo GM: Osteopontin is a prognostic biomarker in non-small cell lung cancer. BMC cancer 2013;13:540.

40 Cao DX, Li ZJ, Jiang XO, Lum YL, Khin E, Lee NP, Wu GH, Luk JM: Osteopontin as potential biomarker and therapeutic target in gastric and liver cancers. World J Gastroenterol 2012;18:3923-3930.

41 Thoms JW, Dal Pra A, Anborgh PH, Christensen E, Fleshner N, Menard C, Chadwick K, Milosevic M, Catton C, Pintilie M, Chambers AF, Bristow RG: Plasma osteopontin as a biomarker of prostate cancer aggression: Relationship to risk category and treatment response. British journal of cancer 2012;107:840-846.

42 Maier T, Laubender RP, Sturm RA, Klingenstein A, Korting HC, Ruzicka T, Berking C: Osteopontin expression in plasma of melanoma patients and in melanocytic tumours. J Eur Acad Dermatol Venereol 2012;26:1084-1091.

43 Filia A, Elliott F, Wind T, Field S, Davies J, Kukalizch K, Randerson-Moor J, Harland M, Bishop DT, Banks RE, Newton-Bishop JA: Plasma osteopontin concentrations in patients with cutaneous melanoma. Oncology reports 2013;30:15751580 .

44 Kluger HM, Hoyt K, Bacchiocchi A, Mayer T, Kirsch J, Kluger Y, Sznol M, Ariyan S, Molinaro A, Halaban R: Plasma markers for identifying patients with metastatic melanoma. Clinical cancer research : an official journal of the American Association for Cancer Research 2011;17:2417-2425.

45 Raso E, Barbai T, Gyorffy B, Timar J: [prognostic and predictive markers of malignant melanoma]. Magy Onkol 2013;57:79-83.

46 Atai NA, Bansal M, Lo C, Bosman J, Tigchelaar W, Bosch KS, Jonker A, De Witt Hamer PC, Troost D, McCulloch CA, Everts V, Van Noorden CJ, Sodek J: Osteopontin is up-regulated and associated with neutrophil and macrophage infiltration in glioblastoma. Immunology 2011;132:39-48. 
